\title{
ESTRELAS NASCEM PARA BRILHAR: A EXPANSÃO DAS FRONTEIRAS DO NARRAR-SE TRANS, SOB OS AUSPÍCIOS DA DEMOCRACIA BRASILEIRA (1998-2008)*
}

\author{
Stars are born to shine: the expansion of frontiers in narrating oneself \\ transgender under the auspicious of Brazilian democracy (1998-2008)
}

\author{
Leocádia Aparecida Chaves ${ }^{1}$ \\ ${ }^{1}$ Universidade de Brasília, Brasília, DF, Brasil. \\ E-mail: leocadiachaves@gmail.com
}

\section{RESUMO}

A produção autobiográfica de autoria trans no Brasil contemporâneo é uma das facetas da literatura trans que, desde 2010, vem conquistando com mais vigor o espaço literário. Neste artigo, tendo em vista a necessidade de um recorte, deter-me-ei nas obras autobiográficas publicadas entre 1998 e 2008, as quais, na abordagem proposta, vêm à tona como enunciações rebeldes em relação ao status apresentado, seja pelo sucesso profissional, no caso de Ruddy Pinho $(1998,2007)$, seja pelo ativismo, como ocorre com a obra de Claudia Wonder (2008). Ambas promovem a dignidade da existência trans pela autoafirmação e/ou autoidentificação.

EDITOR-CHEFE:

Gerson Roberto Neumann

EDITOR EXECUTIVO:

Regina Zilberman

SUBMETIDO: 30.04 .2021

ACEITO: 15.06 .2021

\section{COMO CITAR:}

CHAVES, Leocádia

Aparecida. Estrelas nascem para brilhar: a expansão das fronteiras do narrar-se trans, sob os auspícios da democracia brasileira (1998-2008).

Revista Brasileira de Literatura Comparada,v.23,n.44,p.24-43, set.-dez., 2021. doi: https:// doi.org/10.1590/2596-

304x20212344lac
PALAVRAS-CHAVE: autobiografia, transgeneridade, narrativas de saber, autovalorização, autoidentificação.

\section{ABSTRACT \\ The autobiographical production of transgender authorship in contemporary Brazil is one of the aspects of transgender literature that, since 2010, has gained more vitality in literary space. In this paper, I will focus on autobiographical novels published between 1998 and 2008, all of which came to being as rebel enunciations against the status presented, be it by professional success, as in the works of Ruddy Pinho $(1998,2007)$, be it by the activism, as it happens in the work of Claudia Wonder (2008). Both works promote the dignity of transgender existence through self-affirmation and/or self-identification.}

KEYWORDS: autobiography, transgenderism, narratives of knowledge, self-worth, selfidentification.

\footnotetext{
* Este artigo deriva, substancialmente, da tese de doutorado de minha autoria.
} 
Vi uma estrela tão alta, Vi uma estrela tão fria! Vi uma estrela luzindo Na minha vida vazia.

(Manuel Bandeira, 1967, p. 300-301)

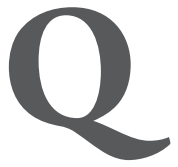

uando nos debruçamos sobre a produção literária de autoria trans no Brasil, irremediavelmente, deparamo-nos com a produção autobiográfica ${ }^{1}$, que, desde 1982 , com a publicação da obra A queda para o alto, de Anderson Herzer, vem se configurando como uma produção que muito tem a nos dizer. De acordo com o levantamento realizado por Amara Moira publicizado nas redes sociais desde $2017^{2}$, e também em confirmação pelas minhas pesquisas, trata-se de um universo de pelo menos $15^{3}$ obras, a saber: Erro de pessoa: Joana ou João? O depoimento de um transexual brasileiro que, nascido mulher, finalmente se realizou como homem, de João W. Nery (1984); Meu corpo, minha prisão: autobiografia de um transexual, de Loris Ádreon (1985); Liberdade ainda que profana, de Ruddy (1998); Nem tão bela, nem tão louca, de Ruddy Pinho (2007); Olhares de Claudia Wonder: crônicas e outras histórias, de Claudia Wonder (2008); Viagem solitária: memórias de um transexual trinta anos depois, de João W. Nery (2011); Eu trans - A alça da bolsa: relatos de um transexual, de Jô Lessa (2014); Meu nome é Amanda: \#trans\#mandycandy\#youtube, de Amanda Guimarães (2016); E se eu fosse puta, de Amara Moira (2016); Vidas trans: a coragem de existir, de T. Brant, Amara Moira, João W. Nery e Márcia Rocha (2017); Trinta anos de reclusão e as memórias de Porcina D’Alessandro, de Porcina D’Alessandro (2017); Nós, trans: escrevivências de resistência, organizada por Maria Léo Araruna (2017); A vida de um transgênero, de Téhh Queiroz (2018) e, por último, Velhice transviada: memórias e reflexões, de João W. Nery (2019).

Trata-se, portanto, de uma literatura que se coloca como convite para a crítica literária contemporânea, que, de forma articulada ao sistema literário, historicamente tem estigmatizado seus produtores e suas produções. Como assevera Jota Mombaça (2015), há décadas, por diversos meios, pessoas vinculadas a grupos populacionais subalternizados, de modo particular a população trans dentro e fora de nosso país, têm produzido conhecimento, porém, como se trata de um conhecimento questionador da ordem, do status quo - aqui evidenciado pelas autobiografias - não têm sido ouvidas. Ouvir, pois, é interromper a lógica colonial que historicamente tem definido quais conhecimentos devem ser reconhecidos e validados e quais não devem sê-lo; quem tem o poder de classificar, hierarquizar, questionar, ensinar. No limite, quem tem (ou não) o poder de ter a sua vida e os seus saberes enunciados como dignos de reconhecimento público.

\footnotetext{
1 Para essa definição, tomo como ponto de partida tanto a metodologia de Philippe Lejeune (2014) quanto as reflexões propostas por Luiz Antônio Marcuschi (2005).

2 Disponível em: https://www.facebook.com/amoiramara. Acesso em: 10 de jul. de 2020. Também disponível em: https://benditasmulheress. com.br/transliteratura-e-transfeminismo-transpondo-preconceitos-de-genero/. Acesso em: 20 de out. de 2020.

3 Se dilatarmos o conceito de autobiografia para obras escritas a quatro mãos, poderíamos incluir os livros A Princesa: depoimento de um travesti brasileiro a um líder das Brigadas Vermelhas (1995), de Fernanda Farias de Alburqueque e Maurizio Jannelli, e Eu, travesti: Memórias de Luísa Marilac (2019), por Luísa Marilac e Naná Queiroz.
} 
Tomando como ponto de partida essa compreensão, vinculada ao pensamento queer brasileiro e às concepções decoloniais, incluindo os feminismos do Sul e o transfeminismo, deter-me-ei neste artigo na produção autobiográfica de autoria trans publicada entre 1998 e 2008, que se impõe pela autovalorização e autodefinição de suas autoras e protagonistas. Sob esse viés, são consideradas escritas rebeldemente revolucionárias, pois garantiram, em um contexto histórico de reconstrução da democracia, que os seus corpos, suas existências ocupassem o espaço público do literário por meio de um narrar-se libertário do enquadramento patologizador.

Como discutem Jaqueline Gomes de Jesus (2010) e Patrícia Hill Collins (2019), a autovalorização e a autodefinição são cruciais na constituição de toda e qualquer subjetividade humana, de forma vital, para as pessoas em situação de opressão cistêmica ${ }^{4}$. Conforme enfatiza Jesus, o direito à autodefinição é garantia primeva para se reconhecer e ser reconhecido como humano, em um processo que vai além de uma identidade civil - apesar de se vincular a ela -, pois se trata do autorreconhecimento como pessoa, sujeito de direitos. Já Collins destaca que a autovalorização permite a formação de autoestima individual com impacto comunitário. Portanto, são processos subjetivos vitais e, por conseguinte, fundamentais para a construção de narrativas pessoais, bem como para a (re)construção de um imaginário social sobre o grupo a que se vincula, uma vez que de suas agências acabam por colocar em xeque definições de controle sobre suas existências. No que se refere à produção de Ruddy (1998, 2007) e Wonder (2008), como demonstrarei, o narrar-se estabelece-se, não fortuitamente, como um importante marco para a nossa história literária, pois autoevidencia-se como uma guinada nos modos do narrar trans em nosso país, que tem perpetuado narrativas deslegitimadoras de suas existências (SOARES; LOPES, 2017).

\section{RUDDY PINHO (1998, 2007) E CLAUDIA WONDER (2008): PELA AUTOAFIRMAÇÃO E AUTOIDENTIFICAÇÃO}

Se as escritas de Herzer (1982), Nery (1984) e Ádreon (1985) nascem em um contexto de certezas sobre a patologização e a medicalização da experiência trans e seus textos se estruturam sob esse eixo, as obras de Ruddy Pinho, Liberdade ainda que profana (1998) e Nem tão bela, nem tão louca (2007), e a de Claudia Wonder, Olhares de Claudia Wonder: crônicas e outras histórias (2008), já nascem em uma conjuntura de questionamento e desconstrução dessas "verdades", o que por modos diferentes acaba por reverberar em suas escritas.

Os livros de Ruddy e Wonder surgem em um contexto em que se evidencia um expressivo engajamento institucional por parte de ativistas LGBT, como demonstra Trevisan (2018) e Cleyton Feitosa Pereira (2017), bem como o crescimento de organizações não governamentais - ONG's protagonizadas por travestis e mulheres transexuais, garantindo, como nunca visto, visibilidade para a causa e para o protagonismo trans (CARVALHO; CARRARA, 2013). A conjuntura, que acelerou debates sobre identidades como lugar político, fomentou alianças e favoreceu o nascimento de organizações específicas para a causa, como, por exemplo, a Articulação Nacional de Travestis, Transexuais e Transgêneros (ANTRA) no ano 2000 (CARVALHO; CARRARA, 2013, n/p).

\footnotetext{
4 Viviane Vergueiro (2015), ao discutir o modus operandi de dominação europeia em nossas sociedades, traz ao debate o conceito de cissexismo, operador potente para o desnudamento dos mecanismos de opressão da cisgeneridade sexista sobre as/os dissidentes da norma cisheteronormativadora. A partir dessa compreensão, refere-se às estruturas de poder pela denominação "cistema".
} 
No âmbito do Estado, como discute Vianna (2015), de forma evidente no governo de Luiz Inácio Lula da Silva (2003-2010), houve uma forte relação entre governo e movimentos sociais em prol de políticas públicas de educação - programas e planos envolvendo diferentes órgãos públicos, organismos e instâncias da sociedade relacionadas - voltadas para o gênero e a diversidade sexual.

No campo das produções acadêmicas, destaca-se o pioneirismo da feminista Guacira Lopes Louro que em 1997 publica Gênero, sexualidade e educação: uma perspectiva pós-estruturalista, obra que vai de encontro aos discursos essencializadores quanto ao gênero e sexualidade, consequentemente, com a biologização identitária, ainda que completamente circunstanciada ao debate sobre os papéis definidos para homens e mulheres cisgêneros sob a normatividade heterossexual. Louro (1997) ancora-se na formação de um pensamento plural que, sob perspectivas múltiplas, indaga o como e o porquê de as representações de gênero e sexualidade se darem da forma como se dão em nossa sociedade, com um debate que se funda na observação de que as concepções de gênero e sexualidade diferem entre as sociedades e até mesmo no interior de cada uma, pois fruto da relação entre diferentes marcadores sociais, como raça e classe, e os múltiplos mecanismos de poder. Pouco depois, ao publicar $O$ corpo educado: pedagogias da sexualidade (2000), Guacira Lopes Louro garante a divulgação da produção de importantes referenciais norte-americanos para o debate sobre identidade de gênero e sexualidade aqui no Brasil, dentre eles, o pensamento de Judith Butler, reconhecida como uma das grandes responsáveis pela construção da analítica queer no Ocidente. Por meio de uma multiplicidade de reflexões, desnuda como as interseccionalidades que atravessam a vivência humana - geração, raça, nacionalidade, religião, classe, etnia, por exemplo - alteram as concepções, as práticas do "ser mulher" e "do ser homem" no Ocidente; um debate que, apesar de ainda não abordar a transgeneridade, trata de questões cruciais nos processos de subjetivação identitária.

Neste mesmo ano, Tomaz Tadeu da Silva, pedagogo e sociólogo, publica duas obras referenciais para essa discussão: Identidade e diferença: a perspectiva dos estudos culturais (2014) e Antropologia do Ciborgue: as vertigens do pós-humano (2000). A primeira, fruto da reunião dos debates efetivados por Kathryn Woodward, Stuart Hall e o próprio autor sobre a necessidade de se discutir a questão da identidade a partir da categoria analítica da diferença e não da diversidade, como até então vinha sendo efetivado pelas humanidades, pois

Na perspectiva da diversidade, a diferença e a identidade tendem a ser naturalizadas, cristalizadas, essencializadas. São tomadas como dados ou fatos da vida social diante dos quais se deve tomar posição. (SILVA, 2014, p. 73)

A partir dessa abordagem, propõe-se uma analítica que tanto garanta o reconhecimento de singularidades nos processos de construção das posições identitárias quanto busque reconhecer como elas são classificadas e fatalmente hierarquizadas em nossas sociedades, uma vez que

A identidade, tal como a diferença, é uma relação social. Isso significa que sua definição - discursiva e linguística - está sujeita a vetores de força, a relações de poder. Elas não convivem harmoniosamente, lado a lado, em campos sem hierarquia; elas são disputadas. (SILVA, 2014, p. 81)

Por meio da publicação de Antropologia do Ciborgue: as vertigens do pós-humano, Tomaz Tadeu Silva (2000) instala o debate sobre "o humano" em diálogo com o seminal "Manifesto ciborgue: ciência, tecnologia e feminismo-socialista no final do século XX”, da cientista e teórica feminista 
Donna Haraway (publicado nos Estados Unidos em 1985). Silva soma esforços tanto para desnudar a promiscuidade entre ciência e política na contemporaneidade tendo em vista seus interesses econômicos, como para questionar o impacto disso nas identidades que historicamente têm se rebelado contra a cisheteronormatividade. A obra do professor catarinense é um convite para reconhecer o humano a partir da imagem ciborgue, pois todas, todos e todes, em algum grau e em algum momento de nossas vidas, seremos reconhecidos como tal.

Em 2006, Berenice Bento, publicando A reinvenção do corpo: sexualidade e gênero na experiência transexual (2006), coloca em xeque tanto os dispositivos de poder-saber medicalizadores sobre a transgeneridade quanto os recortes e abordagens desse campo de saber sobre essa experiência humana. Uma interpelação fortalecida pelos estudos e reflexões da Psicologia brasileira, que passou a reconhecer essa identidade não como enfermidade, mas como um conflito identitário derivado da compulsoriedade identitária infligida pelo status quo. Dentre esses estudos, cito os de Márcia Arán (2006), Tatiana Lionço (2006, 2008), Daniela Murta (2011) e Rafael Kalaf Cossi (2010).

Dessa forma, a conjuntura política, social e acadêmica parece ter sido determinante para que Ruddy Pinho e Claudia Wonder também produzissem uma guinada no modo do narrar-se trans em nosso país. Por meios muito distintos, ao publicarem suas escritas autobiográficas, essas autoras instauram uma radicalidade no tempo em que são publicadas, pois não mais limitadas a se narrarem a partir do eixo da busca de um diagnóstico para efetivação de "tratamento". Ao contrário, aqui vão "aparecer" pela autoafirmação, defesa e valorização da autoidentificação. Se nas escritas de Ruddy Pinho (1998, 2007) a estrutura narrativa orbita em torno do seu sucesso profissional e otimismo diante da vida, "apesar dos pesares"; na de Wonder (2008) se revela uma outra força, a da ativista que, norteada pelo "Manifesto Travolaka", como veremos adiante, apresenta a sua história de vida juntamente à história de outras mulheres trans, igualmente "legitimáveis", portanto dignas da autoafirmação, autovalorização, e cidadãs com direito à autoidentificação, como todo e qualquer ser humano.

Essas publicações irrompem, por isso, como instrumentos revolucionários, pois, apesar dos avanços nas discussões e concepções sobre identidade, das políticas educacionais voltadas para a diversidade sexual entre 2003-2010, do crescimento e fortalecimento do movimento ativista, o estado de exceção cisheteronormativador se mantinha inabalável quanto à estigmatização da existência das pessoas trans. Nesse sentido, vale lembrar que, somente em 2008, conquista-se o direito ao processo transexualizador pelo Sistema Único de Saúde; somente em 2018, o STF reconhece o direito ao autorreconhecimento de gênero ${ }^{5}$, e a Organização Mundial de Saúde retira a transexualidade da lista de transtornos mentais da Classificação Internacional de Doenças (CID-11) ${ }^{6}$; somente em 2019

\footnotetext{
5 Em 2018, o Supremo Tribunal Federal, por meio de uma Ação Direta de Inconstitucionalidade (ADI) 4275, reconheceu o direito de alteração do prenome e gênero no registro civil via procedimento cartorial, sem a necessidade de realização de cirurgia de mudança de sexo, ato ou laudos médicos e psicológicos. Reconhecendo, portanto, a partir do princípio constitucional da garantia da dignidade humana, o direito ao autorreconhecimento identitário. Disponível em: http://www.stf.jus.br/portal/cms/verNoticiaDetalhe.asp?idConteudo=371085. Acesso em: 10 abr. 2018.

6 Em 2018, por força do ativismo de intelectuais e da organização dos movimentos sociais, a Organização Mundial de Saúde (OMS) garantiu a revisão da categoria identidades transgênera e travesti no Manual de Diagnóstico e Estatística dos Transtornos Mentais - DSM-5, quanto à Classificação Estatística Internacional de Doenças e Problemas Relacionados com a Saúde no CID-11. Nessa revisão, a categoria identidades transgênera e travesti serão retiradas do capítulo "transtorno mental" e incluídas no capítulo "condição relativa à saúde sexual", um pequeno passo rumo à despatologização. Disponível em: https://nacoesunidas.org/oms-retira-a-transexualidade-da-lista-de-doencas-mentais/. Acesso em: jul. 2019.
} 
o STF criminaliza a LGBTfobia ${ }^{7}$. Portanto, como demonstrarei, por distintos modos narrativos, essas escrituras revelam-se como importantes contributos para a construção de outros imaginários sobre a transexualidade e, consequentemente, importantes contributos na/para a desconstrução de estigmas sobre suas existências.

\title{
RUDDY, A MARAVILHOSA ${ }^{8}$
}

Quando nos voltamos para a produção literária ficcional de autoria trans no Brasil, inevitavelmente chegamos a Ruddy Pinho, que em 1980 estreia na cena literária com a obra poética Eu, $R u d d y^{9}$. No entanto, como discute Amara Moira (2018), trata-se de uma leitura a posteriori, uma vez que naquele período a autora ainda não se autorreconhecia mulher, tampouco trazia essa questão de forma explícita para a sua escrita, o que ocorrerá somente a partir da publicação de sua primeira autobiografia, Liberdade ainda que profana (1998), a partir de agora identificada como LAP, quando, ao celebrar os 35 anos de carreira como cabeleireira, também se enunciará como mulher:

\begin{abstract}
Em janeiro de 98, dei uma grande festa, comemorando meus trinta e cinco anos de carreira. Fiz um grande happening no dia 29 de janeiro de 1998. Resolvi receber umas 500 pessoas, na própria galeria onde funciona o meu salão. Convidei drag-queens, a Rogéria, a Jane di Castro, Claudia Hazan (que me presenteou com uma dança do ventre), atores, atrizes, clientes, crianças, cachorro, um pouco de um tudo, como deve ser uma festa. (RUDDY, 1998, p. 196)
\end{abstract}

Naquela circunstância, Ruddy já era chancelada como autora e como tal é que enuncia a sua escrita autobiográfica: "É como escritora que dou meu testemunho de vida, tenho oito livros publicados, não sou apenas uma personalidade tecendo comentários ou contando situações. [...] Pretendo editar muitos” (RUDDY, 1998, p. 7). Tal “validação” astutamente parece ser mobilizada tanto para afirmar a qualidade de sua escrita, quanto o valor de sua vida: uma mulher trans que conquistou reconhecimento profissional e literário e patrimônio financeiro.

Dando continuidade ao seu projeto autobiográfico, em Nem tão bela, nem tão louca (2007), a partir de agora identificada como NBNL, Ruddy deter-se-á fundamentalmente nos fatos, experiências, conquistas e desafios vivenciados nos últimos anos do segundo milênio, dentre eles, as memórias de suas muitas viagens para a Europa e os Estados Unidos e o seu pleito a uma cadeira na Academia Brasileira de Letras. Elementos narrativos que parecem ser mobilizados de forma mais contundente tanto para confirmar a sua inserção social pelo consumo quanto para colocar em xeque, pela autoafirmação e autodefinição, o cistema que a violenta: "Quero com esse livro denunciar as alegrias e dificuldades em

\footnotetext{
7 Em 2019, o Supremo Tribunal Federal, por meio da Ação Direta de Inconstitucionalidade por Omissão (ADO) 26 e pelo Mandato de Injunção (MI) 4733, determinou que a conduta da homofobia e da transfobia fossem punidas pela Lei de Racismo (7716/89), que prevê crimes de discriminação ou preconceito por "raça, cor, etnia, religião e procedência nacional”. Disponível em: http://www.stf.jus.br/portal/cms/ verNoticiaDetalhe.asp?idConteudo=414010. Acesso em: jul. 2019.

8 Essa qualificação, conforme narra a autora, advém de uma coluna escrita por Danuza Leão no JB em 1992 sobre a singularidade de seu trabalho: "Contei meu problema e ela, na sua coluna do $J B$, fez a denúncia e ressaltou que, além de eu ser a verdadeira Ruddy, eu era 'a Ruddy, a maravilhosa'. [...] Esse bordão se ajustou com perfeição à minha imagem, de modo que onde chego, algumas pessoas já exclamam: 'Ruddy, a maravilhosa!'” (RUDDY, 1998, p. 141). O “bordão", como afirma, ajustado a sua imagem, confirma-se, como demonstrarei, nos modos como se narra em ambas as autobiografias, pois enaltecedoras de suas competências e sucesso profissional.

9 Data de nascimento por volta do ano de 1940 (RUDDY, 1998).
} 
ser diferente e chegar à maturidade em um país completamente ignorante a respeito das diferenças.” (RUDDY, 2007, p. 11). Sua escrita, como ela mesma confirma, é desafiadora, pois

A diferença entre este e os outros livros que escrevi é que contar sua própria vida, sem ficção, é muito difícil. Preciso estar disposta para enfrentar possíveis críticas e incompreensões. Mas ao mesmo tempo agradeço e dispenso isso tudo, sempre fui transgressora e orgulhosa por ter sobrevivido de arte, no Brasil. É aqui que quero envelhecer, mesmo que me considerem uma eterna polêmica. (RUDDY, 1998, p. 217-218)

\title{
LIBERDADE AINDA QUE PROFANA (1998)
}

Como já mencionado, LAP (1998), diferentemente das autobiografias publicadas nos anos de 1980, nasce, simultaneamente, como manifesto de alguém que desde sempre lutou pela sua dignidade e no presente coroa uma trajetória de sucesso:

\begin{abstract}
Denuncio e protesto contra a sociedade que ignora seu semelhante. Mas faço um protesto light, diet, coberto de strass e purpurina para não deixar de ser alegre e feliz. [...] Não é justo que meu sofrimento comprometa o resultado final. [...] Amei, dei o melhor de mim ao meu semelhante tornando-o mais belo esteticamente. Fiz cabelos de mais de 300 mil pessoas nestes 35 anos de trabalho, e meu talento sempre foi recompensado. [...] Meu depoimento de vida vem em uma hora em que estou feliz, encontrada e cheia de planos para o próximo milênio. Daqui a pouco vou me aposentar pelo INSS, mas continuarei atendendo minha clientela com carinho e a vontade de sempre. Talvez, viver mais no meu mato junto à Iansã, e vez por outra sair pelo mundo. Quero que fique bem claro que minhas experiências desagradáveis jamais me tiraram as minhas origens. [...] Sou uma artista que se expressou de várias formas e tenho orgulho de dizer que sou brasileira, tenho muito orgulho disso. (RUDDY, 1998, p. 7)
\end{abstract}

O deslocamento narrativo acima apresentado é surpreendentemente subversivo, no contexto em que se inscreve, pois, embora a questão da transição de gênero - desafios, descobertas, cirurgias de redesignação sexual - inextrincavelmente organize a sua trajetória de vida, o seu narrar-se transborda esse aspecto, fraturando uma expectativa da narrativa de si própria. Por consequência, capaz de vingar um enquadramento de morte para existências como a sua, uma vez que, além de enaltecer e confirmar a autovalorização, por conseguinte, o seu processo de autoidentificação, faz isso como uma cidadã que, ao comemorar 35 anos de carreira como cabeleireira, ainda tem muito orgulho de dizer que é brasileira.

Dessa forma, ao celebrar a carreira, a autora também celebra a vida e, estrategicamente, debocha do status quo já no título da obra: Liberdade ainda que profana! Assim, paradoxalmente, mesmo enunciandose como uma cidadã sob os auspícios da democracia garantida pela Constituição de 1988, igualmente denuncia essa liberdade como incompleta, já que se sabe reconhecida pela Ordem patriarcal como profanadora dos desígnios de Deus e dos homens consolidadores do regime identitário compulsório que a cerca. Um deboche reforçado na ilustração da capa, uma autorrepresentação espelhada na irreverente Marilyn Monroe, acompanhada de uma assinatura igualmente irreverente: Ruddy, a "maravilhosa".

Destaca-se que, já nas primeiras páginas, ao buscar "o fio da meada” de sua carreira como cabeleireira, Ruddy (1998) revela que tal ocorre por volta dos 13-14 anos, em meados dos anos de 1950 em Belo Horizonte, quando perde o emprego na Drogaria Araújo por homofobia: “- Você é bicha, não é? Não dá para continuar, fica mal para a farmácia. Vá procurar a sua turma! E eu fui!” (RUDDY, 1998, p. 27). 
A demissão acabou por levá-la a ser explorada sexualmente na Zona Boêmia de Belo Horizonte, mas também contribuiu para que se aproximasse da estética e do cuidado feminino:

O salão de Maria Sabina ficava em um local modesto, próximo à Zona, cuja clientela era basicamente composta por veados e prostitutas. Lá aprendi os primeiros segredos da profissão. Aprendi a armar cabelos sensuais e duradouros, que não desmanchavam enquanto as putas atendiam seus clientes. Aprendi a transformar mulheres em deusas e fui, aos poucos, criando um estilo. (p. 47)

Interessante notar que, se por um lado ela denuncia a exclusão que sofreu no mercado de trabalho formal, de forma maravilhosamente atrevida, ao dizer da Zona Boêmia, o diz como uma grande oportunidade de profissionalização, pois as “putas eram exigentes!”. Registra ainda que, depois do salão de Maria Sabina, trabalhou no lendário Hotel Maravilhoso, onde moravam as prostitutas mais famosas da cidade, dentre elas Hilda Furacão, o que lhe garantiu, pouco tempo depois, empregabilidade no Salão mais requintado de Belo Horizonte, o Charme:

Alguém indicou o meu nome, dizendo que eu trabalhava no Hotel Maravilhoso. Dona Hilda, mais que depressa, pediu que me chamassem, dizendo que se eu trabalhava para as putas, mulheres reconhecidamente exigentes, deveria trabalhar bem. (p. 48)

Foi nesse salão que passou a ter contato com a burguesia tradicional mineira, hermética e repressora, o que lhe impôs um grande "desconforto", mas depois “[...] passou [a ter uma convivência] absolutamente natural, sem arestas” (p. 49-50). Nota-se que, ao dizer desse trânsito profissional, revela-o também como subversivo, pois fora exatamente o "artesanato" aprendido na Zona Boêmia que garantiu o sucesso com a elite da capital mineira: “[... trazia para a sociedade a magia da Zona, e criava penteados mais soltos, mais leves, mais sedutores. Isso me dava enorme prestígio junto à clientela” (p. 49-50). Tal prestígio foi engenhosamente manejado pela protagonista para driblar a repressão política em Belo Horizonte. Quanto a isso, com ironia e perspicácia, relata sua participação como "coadjuvante" em uma ação estudantil de resistência ao regime ditatorial:

Em um dia deste ano (1964) fui presa pelo DOPS mineiro, em uma reunião de estudantes no DCE. Tinham me pedido no salão que levasse uma carta para alguém, não lembro mais quem era. Eu fui e havia uma reunião acalorada, tipo comício. Chegou a polícia e lá fui eu, de gaiata. Passei uns tempos presa e nem ao menos registraram meu nome em lugar nenhum. Poderiam ter me matado e ninguém saberia. Os caras do exército me deram uns tapas, e depois me soltaram. Mas passaram a me perseguir nas ruas quando me viam, mesmo sendo cabeleireira conhecida na cidade, sem frequentar a Zona Boêmia. (RUDDY, 1998, p. 50)

Observa-se que, se por um lado Ruddy revela a sua participação como ingênua e despretensiosa: "lá fui eu de gaiata"; por outro, acaba por irromper-se como uma sobrevivente denunciante do regime de ditadura no contexto democrático: "Passei uns tempos presa e nem ao menos registraram meu nome em lugar nenhum. Poderiam ter me matado e ninguém saberia”. Uma perseguição que determinou que se exilasse no Rio de Janeiro no ano de 1965, onde, erroneamente, acreditava estar a salvo:

O Exército continuou a implicar comigo aqui no Rio. Sempre achava um motivo para querer me entrevistar, cortar meus cabelos ou me achincalhar. Cheguei a ser detida no final dos anos de 1960 para servir de faxineira em delegacias e quartéis. Quando não era polícia, era o exército. Muitas vezes fui usada sexualmente por alguns deles. Às vezes participava, outras me sentia estuprada. Nunca pude reclamar, mas um dia chegou a minha chance. (RUDDY, 1998, p. 51) 
Já nos salões da cidade - "trabalhava no New Maritê Cabelereiros, em Ipanema. [...] Foi ele quem me deu o grande empurrão na arte de pentear. [... conheci gente fantástica” (RUDDY, 1998, p. 71) -, conquistava uma clientela que variava desde a elite endinheirada, misses e celebridades de TV a cantores e cantoras vinculados à contracultura:

Conheci a Léa Maria, colunista do Jornal do Brasil quem primeiro publicou meu nome em grande destaque. Passei a ter contatos mais próximos com artistas, como Leina Crespi, Gal Costa e Maria Bethânia. (RUDDY, 1998, p. 71)

Como exemplo de um talento e uma estética singulares, cito o seu registro de sucesso com o corte de cabelo da cantora Simone:

Quando conheci Simone, ela estava em início de carreira, e fui eu quem criou aquele estilo leonino, cabelereira solta e volumosa, que por anos exibiu nos palcos [...]. Um estilo de corte que foi um dos seus grandes sucessos. A partir daí, eu passei a cortar uma série infindável de cabelos iguais aos dela. Virou moda. (RUDDY, 1998, p. 83)

Destaca-se que ao narrar-se genial simultaneamente revela-se portadora de uma habilidade artística nata, bem como alguém que buscou formação-qualificação teórica. Como observa, nos anos de 1980 foi “[...] a Paris fazer um estágio no Institute Internacional des Arts de La Coifure, que brasileiro nenhum tinha sido convidado a participar [...]" (RUDDY, 1998, p. 167). Lá, aproveitou a oportunidade para estudar penteados afro e se aproximar da estética punk londrina. Quanto à estética afro, afirma ter sido um sucesso no Brasil: "Iesa Rodrigues, na época editora da revista Vogue, elogiou muito, estampando matéria com a Betty Lago cheia de trancinhas” (RUDDY, 1998, p. 73). Uma genialidade que lhe permitiu "fazer a cabeça" de uma infinidade de personalidades internacionais.

No entanto, sua carreira também foi suscetível às intempéries históricas, como enuncia. Com ascensão até os anos de 1990, teve a vida abalada pela crise econômica, o estigma da AIDS e a perda da marca "Ruddy" junto ao Instituto Nacional da Propriedade Industrial (INPI).

O ano de 1992 foi terrível para mim. A economia do país estava em declínio, a AIDS tinha feito vítimas muito próximas. As clientes se afastavam dos salões, com medo de contágio, ignorância pura, é claro. Às vezes, levavam até canequinhas para tomar café, evitando usar as do salão. (RUDDY, 1998, p. 140)

Nesta elaboração, denuncia tanto a violência que a comunidade LGBT sofreu naquele período, como enfatiza a sua influência e o seu reconhecimento junto à imprensa para contornar a situação:

Liguei para uma mulher a quem eu admirava há tempos e pedi ajuda. Essa mulher era a maravilhosa Danuza Leão. Contei meu problema a ela, na sua coluna no $J B$, fez a denúncia e ressaltou que, além de eu ser a verdadeira Ruddy, era Ruddy, a maravilhosa. (RUDDY, 1998, p. 141)

Salienta-se ainda que em $L A P$, Ruddy, além de se narrar pela carreira de cabeleireira - o que me surge como um fio condutor de sua autobiografia -, também evidencia, ainda que de forma mais pontual, a de escritora, retomada com mais verticalidade na sua segunda autobiografia, como veremos mais adiante, e a de atriz, qualificações que certamente contribuíram para suas inúmeras participações em programas de TV, bem como em entrevistas a revistas e jornais ao longo dos anos de 1980 sobre a temática da homossexualidade e da transexualidade. 
Importante destacar que, ao avaliar suas participações em programas televisivos, enuncia que todas foram bem-sucedidas, exceto uma no Programa da Hebe Camargo em 1987, quando usavam o programa para “[...] conden[ar] as bichas - um ou outro defendia - e só quase no final é que me permitiram entrar. Como ré, é claro, e sem direito à defesa, já que a produção tirou o som do meu microfone logo após o meu 'Boa noite'” (RUDDY, 1998, p. 96).

Tais “aparecimentos", destacados em seu narrar, parecem-me reveladores do seu "engajamento" e de sua consciência sobre o papel que teve para os dissidentes de gênero-sexualidade, que nesta passagem se mostra signo de sua autobiografia: "Programas sobre homossexualidade ou transexualidade, para mim, só são importantes se ajudarem a forma da opinião pública. Nunca me dei mal nesse tipo de entrevistas, a não ser uma vez" (RUDDY, 1998, p. 96). O narrar-se de Ruddy, pelos elementos apresentados e muitos outros não abordados aqui, confirma a autora-narradora-protagonista como sobrevivente às múltiplas violências na ditadura e a um cistema transfóbico ainda vigente no contexto de publicação da sua obra. Portanto, ao escrever a sua história de vida de forma também celebrativa e publicizá-la no contexto que o faz - 10 anos de Constituição Cidadã, 10 anos de (re)construção da democracia, 10 anos de realização de suas cirurgias de redesignação sexual -, Ruddy acaba por também celebrar a existência trans como uma bandeira: “[...] e por isso o título desse trabalho é inspirado no lema da bandeira mineira: 'Libertas Quae Sera Tamem'” (RUDDY, 1998, p. 217).

\section{NEM TÃO BELA, NEM TÃO LOUCA (2007)}

Já NBNL (2007), como a própria autora explicita, está "Longe de ser uma nova biografia, uma vez que dá continuidade ao que já foi contado anteriormente" (RUDDY, 2007, p. 10), inclusivamente, ao "acerto de contas" com o cistema, uma vez que, de largada, novamente, no título da obra, a autoranarradora-protagonista se insurge contra dois estigmas (GOFFMAN, 1988) que desde sempre a violentaram: o da beleza e o da loucura:

$$
\begin{aligned}
& \text { - É bicha. } \\
& \text { - Mas é linda. } \\
& \text { - Mas é louca. } \\
& \text { —É bela e louca. }
\end{aligned}
$$

Algumas pessoas já fugiam de mim, por causa de minha exuberância, e beleza.

Fiz invejosos. Mas tive sempre que conviver com vários estigmas que acabei me acostumando. (RUDDY, 2007, p. 272)

Quanto a esse aspecto, importante notar que, se por um lado, Ruddy diz ter se acostumado aos estigmas; por outro, de forma ambivalente, renuncia a eles por meio de um "nem tão". Tais percepções também são contestadas pela imagem que usa na capa do livro $N B N L$, pois, diferentemente de $L A P$, a autora aparece vestida e ornada com sobriedade, em uma "composição" contrariadora da expectativa criada para corpos como o seu, historicamente construídos como "prontos para o sexo". Uma territorialização, como desabafa, capaz de tornar a sua vida "Um inferno sexual que [a] persegue até hoje" (RUDDY, 2007, p. 73).

Os estigmas acima referidos também serão colocados em xeque por meio de uma narrativa que, além de dar continuidade a uma escrita de autoafirmação, autovalorização como uma cabeleireira de sucesso que é, evidenciará tanto a sua carreira literária como uma escritora que concorreu a uma cadeira 
na Academia Brasileira de Letras $(\mathrm{ABL})$ - nota-se que usará NBNL inclusive para promover alguns dos seus escritos ficcionais - quanto o acumular de muitas memórias de viagens turísticas internacionais.

O seu projeto de ocupar um assento na $\mathrm{ABL}$ é desenvolvido logo depois de o seu livro de contos In... confidências mineiras e outras histórias (1999) ser premiado pela Biblioteca Nacional, ocasião em que Antônio Houaiss falece: "Entrei em um concurso da Biblioteca Nacional, ganho o primeiro lugar e me candidato à Academia Brasileira de Letras. Ousada, diriam. E por que não?” (RUDDY, 2007, p. 38). Ao confirmar a sua habilitação para a concorrência, também enfatiza a sua ousadia, comportamento equiparável ao da rebeldia de que nos fala Butler (2018), pois responsável pela sua coragem em enfrentar as limitações impostas pelo status quo. Dessa forma, exercendo mais uma vez o seu direito à cidadania, interpela: "por que não?”.

Com todo direito, pois brasileira, solteira, loura com mais de 21 anos e escritora de oito livros. Era
minha hora. Aliás, bem pensado. Além de me candidatar à sua vaga ainda o homenagearia. É que, uma
vez, há muito tempo, ele me mandou uma carta. Isso mesmo! O filólogo mais importante do país me
escreveu uma carta parabenizando-me por um dos meus livros. Também porque ele me havia visto no
programa "Sem Censura" da TVE [...] e ele percebeu que eu não dissera nada errado em meu português.
(RUDDY, 2007, p. 71)

À indagação (“por que não?”), Ruddy responde com argumentos plausíveis - ser brasileira, maior de 21 anos, escritora - e não plausíveis, como "ser loura e solteira”. E vai mais além, pois confirma-se como alguém digna para substituir o filólogo mais importante do país, o que seria igualmente uma homenagem a ele. Esses elementos são reveladores da estética despudorada e escarnecedora com que a autora compõe a sua escritura, já enunciado em LAP (1998), "Escrevo despudoradamente, despudor que adquiri no teatro, e como atriz performática que sempre fui, percebo que venho interpretando diversos personagens ao longo da vida" (RUDDY, 1998, p. 217), e confirmado na abertura de NBNL (2007), quando enuncia aproximar a estética de sua escrita a do escritor Nelson Rodrigues.

$\mathrm{Li} \mathrm{e}$ assisti a tudo que tive acesso no teatro, cinema, a qualquer coisa que este monstro sagrado nos deixou de herança. Como nas obras de Nelson, eu também me desnudo diante de meus desejos, minhas histórias de vida sem pudor - mas com dignidade tiro a roupa de minha personagem. (RUDDY, 2007, p. 9)

Porém, ao narrar a sua determinação à candidatura a uma cadeira na $\mathrm{ABL}$, enfatiza que a empreitada lhe exigiu muitos esforços: "E lá fui eu à Academia para a candidatura. Passei a frequentá-la nos coquetéis e exposições para dar de cara com alguns deles” (RUDDY, 2007, p. 71-72); o que, por outro lado, também lhe permitiu conquistar os holofotes da imprensa, o que soube usar a seu favor.

Fui fazer o programa do Jô Soares pela segunda vez. Na primeira, fui para procurar uma editora e até declamei uma poesia minha ao lado do piano. Na segunda, eu estava como candidata à Academia. (RUDDY, 2007, p. 72)

Quanto à recepção dos meios de comunicação, registra que "A imprensa me deu a maior força. Só elogios, não me lembro de nenhum contra." (RUDDY, 2007, p. 72). Salienta ainda que o próprio Jô “[...] me deu força dizendo logo que o autor João do Rio era gay. Abafa” (RUDDY, 2007, p. 72).

O percurso cumprido por Ruddy em direção à $\mathrm{ABL}$, apesar de não ter resultado na vaga desejada, é registrado com altivez e ironia: "Mas ninguém votou em mim. Azar. Não sou mulher de chazinho. Sou mulher de champanhe” (RUDDY, 2007, p. 72). 
Ainda sobre a sua carreira de escritora, compartilha o convite que recebera de um pastor para escrever sobre o trabalho de sua esposa e filha nas prisões cariocas. Ao descrever a pesquisa para a escrita, reconstrói algumas de suas memórias do cárcere no período da ditadura, em expansão às enunciadas em $L A P$, trauma que a impediu de prosseguir com o contrato de edição do livro proposto:

Respirei fundo e pensei, como Deus é onipresente - eu já fui presa, banida pela sociedade, venci e estou aqui para fazer um trabalho de pesquisa na recuperação de detentos pelo evangelho. Eu uma pecadora, isto só pode ser coisa de Deus. [...] Fui prisioneira da falta de fé - e senti que ela transbordava nos olhos e corações de Alarcon e dos presos. (RUDDY, 2007, p. 206-207)

Tal episódio irrompe em sua escritura tanto para evidenciar que também ela é “filha de Deus”, pois validada para escrever a história das missionárias, contrariando, mais uma vez, os estigmas produzidos para a sua existência, quanto para rodriguianamente - filiação que enuncia no prefácio de $N B N L$ debochar do cistema, uma vez que revelará o fracasso da família do "bom” pastor:

Minha pesquisa era para escrever um livro encomendado por um pastor. Desisti do dinheiro e não escrevi o livro - saí de lá chocada. Tempos depois, eu soube que Alarcon havia deixado o pastor e estava vivendo com um ex-detento. Sua filha também. (RUDDY, 2007, p. 207)

Assim, burlescamente, usa o fracasso do seu projeto literário para dizer o fracasso da "família de bem".

Quanto às suas narrativas de viagem internacional, em maior abundância em $N B N L$, seja pelo enfoque da narrativa, seja pelo acúmulo de vivências, revelam-se como uma outra potência autoafirmadora, pois forte contributo para a quebra do estigma do trânsito internacional de pessoas trans para a prostituição ${ }^{10}$, muito embora não omita, como qualifica Moira (2018), alguns dos seus dramas de classe média, bem como as violências sofridas nas alfândegas, imigrações e consulados. Narrativas que a despeito de aqui e acolá trazerem episódios de encontros amorosos picantes, o que pode fazer parte de qualquer narrativa de viagem de uma pessoa adulta, revelam, sobretudo, a agência da mulher que construiu uma jornada invejável de mobilidade internacional:

Ao longo desses meus anos de vida, diversas vezes, voltei aos Estados Unidos e Europa. Viajei bastante. Conheci povos e países que desejava conhecer. Circulei no mundo por minha conta. Não dependia mais de ninguém, já era cabeleireira famosa, tinha apartamento próprio e ganhava um bom dinheiro. Foram viagens fantásticas, que me enriqueceram espiritualmente, satisfizeram minha fome do belo, minha sede de arte. Quando afinal fui à Dinamarca, país que me deu a verdadeira definição, me transmutei para sempre. ${ }^{11}$ (RUDDY, 1998, p. 151)

A título de exemplo, destaco aqui algumas dessas viagens, como a realizada para os Estados Unidos em fins do ano 1999 e início de 2000, quando acabara de se separar do marido e sente muitas saudades de seu filho. Uma viagem planejada como em um “passe de mágica” apesar de sua fragilidade emocional: "Arrumei forças. Como o Ivan não voltaria, resolvi ir até San Francisco para rever meu filho e tentar sair daquele estado depressivo" (RUDDY, 2007, p. 53-54). Fragilidade essa que também não lhe poderia impedir de pensar na maneira mais apropriada para se vestir: "Coloquei meu velho terninho

10 Sobre a temática, consultar Gênero, sexo, amor e dinheiro: mobilidades transnacionais envolvendo o Brasil, de Adriana Piscitelli et al. (2011).

11 A autora usa o verbo "transmutar" para dizer das cirurgias de redesignação de sexo. 
preto de viagem (vou assim para não chamar tanta atenção) [...]” (RUDDY, 2007, p. 53-54), uma vez que sabe ser alvo do estigma da prostituição internacional (PISCITELLI et al., 2011).

Interessante notar que, ao relatar sua experiência, Ruddy enaltece toda a determinação e capacidade de consumo para "dar a volta por cima". Ao descrever o roteiro que programara e executara, ainda que de forma intempestiva, compartilha com os leitores toda a logística pensada para retornar por Nova Iorque, cidade que faz questão de registrar como familiar. "Desembarquei em Nova York já no pique da cidade. Rápida, peguei um táxi em New Wark e rumei para Manhattan, onde sempre me hospedo na Rua 49, esquina com a 7a, em plena Times Square.” (RUDDY, 2007, p. 56)

Já em 2002, ela tem a oportunidade de apresentar Nova Iorque ao filho, que, mesmo tendo morado na cidade, não conhecida o Harlem como ela: "Mãe, agora eu conheço Nova York e foi você que me mostrou" (RUDDY, 2007, p. 65). Tal conhecimento custou-lhe uma experiência desgastante poucos anos depois, quando ciceroneou um casal de brasileiros brancos pelo bairro negro. O Harlem, a propósito, ganha um capítulo à parte, quando se deterá em descrever a sua efervescência cultural. “Todas as vezes que eu vou a NY visito o Harlem, o famoso bairro negro de onde surgiram tantos talentos, tantas divas do jazz que embalaram nossos corações” (RUDDY, 2007, p. 81). Uma cidade que ao fim e ao cabo não a intimida, uma vez que também tem conhecimento em línguas estrangeiras:

Lost again (perdida de novo)! Para os menos afortunados a tradução é necessária, pois me considero privilegiadíssima por Deus, por conhecer boa parte do mundo e ser entendida em inglês e francês. Ainda arranho um portunhol e o italiano, pois tenho irmã que vive em Roma [...]. (RUDDY, 2007, p. 133)

De forma relativamente sequencial, suas muitas narrativas de viagem são tecidas de modo a revelar a sua primeira década de vida do novo milênio: entre uma viagem e outra, em uma viagem e em outra. Narrativas que, sobretudo, nos dão acesso a uma mulher cosmopolita, cidadã do mundo. Dentre as narrativas de viagem para a Europa, destaco as realizadas para Paris nos anos de 1999 e 2004. A primeira, quando na virada do ano, com amigas e amigos: “[...] estava em Paris no Dauphiné Hotel, em Saint Germain. Sempre fiquei neste quartier, que me é muito familiar, de onde sei sair para qualquer lugar de metrô ou a pé” (RUDDY, 2007, p. 67). Durante a viagem é surpreendida com a notícia da premiação da Biblioteca Nacional:

Eu acordei depois do meio-dia do $1^{\circ}$ dia do ano 2000 em Paris. [...] Foi aí que me dei conta de que, na minha conta no Banco do Brasil, estava depositado o meu prêmio de $1^{\circ}$ lugar. Comemorei com um champagne logo cedo. Voltei para o Brasil para ir receber minha comanda ou diploma da Biblioteca das mãos de Eduardo Portela, Ministro da Cultura [...]. (RUDDY, 2007, p. 69)

A viagem de 2004, realizada com mais duas amigas, confirma o protagonismo de mulheres emancipadas que farão um tour pela Europa: de Paris para Torreilles, depois Cote D’Azur, Mônaco, Roma e retorno a Paris. Quanto ao roteiro em Roma, faz questão de enunciá-lo em comparação com os realizados em fins dos anos de 1970,

[...] em 1977 [...] fiz a Roma turística, na companhia de meu amigo Jorge Askar que lá fazia sua pósgraduação em arquitetura. Foi a viagem mais proveitosa porque, com o Jorge, pude entender melhor a cidade. Voltei mais umas duas vezes nos anos de 1980 com minha irmã Simone, que lá ficou casada. Agora viajo com estas duas loucas. (p. 241) 
Sua agenda inclui desde a participação na missa rezada pelo Papa João Paulo II - que “[...] estava em baixa por causa de certas declarações à imprensa sobre homossexuais, mas que emocionou muito a Lena, [...] que ligou pra Lílian, a namorada de anos, prá dizer: - Tô aqui em Roma com o Papa. E chorava" (p. 243) - até visitas a monumentos como o Coliseu.

Passamos um fim de semana em Roma, indo de Mercedes dirigida pelo Alfredo [o seu cunhado], a todos os monumentos históricos que todo mundo sabe que tem: Coliseu, Partenon, Piazza di Spagna, até (uff, cansei!) chegar ao Vaticano, na hora da missa de São Pedro. Porque era 29, dia do Santo e data nacional do Vaticano. (RUDDY, 2007, p. 242)

No retorno a Paris, prestes a voltar ao Brasil, dedica-se a compras na Galeria Lafayete, visita a Versailles, “[...] onde até parece que [fora] criada, pois o conhe[ce] todo pela oportunidade de visitálo em cada ida a Paris" (p. 249), e Monmartre “[...] onde circulamos entre os pintores e suas telas expostas nas ruas" (p. 250).

Portanto, um conjunto de memórias de viagens que nos faz deparar com uma protagonista que se comprova digna para o aparecimento público, pois, à revelia de um cistema transfóbico, impõe-se como uma consumidora que também conquistou capital cultural ${ }^{12}$ (BOURDIEU, 2007), legitimador e hierarquizador de vidas em nossa sociedade.

\section{CLAUDIA WONDER EM OLHARES DE CLAUDIA WONDER: CRÔNICAS E OUTRAS HISTÓRIAS (2008)}

A obra Olhares de Claudia Wonder: crônicas e outras histórias, de Claudia Wonder (2008), reconhecida aqui como autobiográfica, é composta de uma variedade de gêneros textuais - crônicas, entrevistas, relatos biográficos e autobiográficos -, escritos e publicados, entre 2003 e 2008, na revista G Magazine, um dos periódicos mais representativos e assumidamente militante pela causa LGBT no país durante o período que compreende desde os anos de 1997 a 2009 (FRANÇA, 2010; TREVISAN, 2018). Como afirma a autora, a sua coluna representava "Um desafio e uma grande conquista", pois era um dos poucos espaços na imprensa nacional onde poderia pautar a questão trans, "um universo pouco conhecido, composto de travestis, transexuais, transgêneros e intersexos ${ }^{13}$ ” (WONDER, 2008, p. 11) e, por esse modo,

[...] elucidar as pessoas de um modo geral em relação a essa realidade, e também, com isso, repelir o preconceito que todo desconhecimento pode causar. Mas devo lembrar que ainda não existe uma "verdade" sobre esse tema, pois como o leitor poderá perceber, a cada momento surgem questões sexuais e de gênero. Trata-se de tema ainda carregado de muito tabu, em relação ao qual "autoridades" médicas, religiosas e políticas ainda discordam e, pior ainda, se mobilizam para continuar nos relegando, com todos os meios e mecanismos, à invisibilidade e à marginalidade. (WONDER, 2008, p. 12)

\footnotetext{
12 De acordo com Bourdieu (2007), o capital cultural é um dos recursos manejados pelas elites para perpetuarem as hierarquizações sociais e consequentemente se manterem no poder. Esse recurso pode ser identificado como institucional, objetivado e incorporado. Em se tratando da formação do capital cultural da escritora Ruddy, conforme nos narra, se deu apesar do cistema de exceção que a cercou, fundamental e extraordinariamente pelo modo incorporado e objetivado, pois obrigada a abandonar os estudos escolares formais ainda na pré-adolescência (RUDDY, 1998) e, de origem pobre, contou apenas com o próprio mérito para essa construção.

13 "A intersexualidade é um termo utilizado desde o século XX para o que se conhece no senso comum como hermafroditismo, isto é, a condição de indivíduos que nasceram com órgãos sexuais ambíguos. A linguagem biomédica marca tal condição como patológica, sendo compreendida como resultado de uma interação anormal dos fatores genéticos e hormonais ligados ao gênero no período pré-natal, e a denomina de distúrbio do desenvolvimento sexual (DDS)" (GAUDENZI, 2018, p. 1).
} 
Essa conquista lhe permitiu evidenciar questões essenciais sobre o universo trans feminino, bem como escrever e publicitar a sua versão sobre si. Assim, se na coluna a sua história vai surgindo esparsamente ao longo dos anos, na obra ela ganha visibilidade pela forma como o livro é organizado.

Quanto à forma, importante destacar que, não fortuitamente, Wonder faz aparecer no livro - da página 1 à página 165 (já ao final) - uma sequência de sete fotografias que, intercalada aos textos, ajuda a "narrar" sua história de vida e a sua transição de gênero. Assim, entre a fotografia da abertura - a criança ainda "menino" - e a última - a mulher exuberante que se tornou -, a leitora ou o leitor acessam a história da ativista e o seu ativismo "disseminados" ao longo de toda a obra, em uma composição autobiográfica articulada a "uma comunidade" de partilha, de afetos, que também enuncia e à qual se vincula (nascimento, 2018a, 2018b).

Quanto ao conteúdo narrativo, Wonder "aparece” tanto pela explicitação do "eu” como pela composição do "nós", perceptível nos cinquenta e três textos que compõem as sete seções do livro: "Trabalho e profissão"; "Entrevistas"; "Identidade de gênero"; "Outras histórias"; "Perfis"; "Preconceito" e "Religião”. Destes, 38 são crônicas, seis entrevistas e nove perfis. A explicitação do "eu” se efetiva tanto por meio de suas crônicas claramente autobiográficas quanto no modo como mobiliza suas vivências e memórias para pautar as questões sobre o universo trans e o regime de exceção cisheteronormativador. Já o "nós" se compõe pela articulação de sua história de vida com as pautas que maneja, quais sejam: garantia da visibilidade e espaço de enunciação para os corpos trans; o respeito às diferenças; a implosão dos rótulos que escondem as mil formas de se existir trans; a defesa do direito de propor novas formas de entender e construir o próprio corpo; o direito à ambiguidade de gênero e a despatologização dessa identidade.

Todas essas pautas são defendidas pelo Manifesto da Guerrilha Travolaka, composto pelo Coletivo Cultural Espaço Impróprio, publicado em uma crônica intitulada "Guerrilha Travolaka: Sem armas e com muita bravura, a proposta de uma revolução necessária” (WONDER, 2008, p. 71), tornando-se, de acordo com a leitura proposta, eixo estruturador da obra, uma vez que sustenta a reivindicação de viver a identidade de gênero e consequentemente a sexualidade sem ter de pedir permissão.

Não acreditamos em disforia de gênero nem nos transtornos de identidade. Não acreditamos que somos loucos ou doentes, mas acreditamos sim na insanidade do sistema. Não nos classificamos por sexos, somos todos diferentes e independentes de nossos genitais, nossos lábios, olhos e mãos. (p. 72)

Para defender o direito de existir sob mil formas trans, por exemplo, a autora narra a sua trajetória de autorreconhecimento, o que vai de encontro à certeza essencializadora, biologizante quanto ao gênero também em contestação pela produção acadêmica, como demonstrado anteriormente. Na crônica "Em busca de formas mais harmoniosas", distanciada da compreensão de que havia "nascido em um corpo errado", Wonder evidencia que passou a se reconhecer travesti em função da homofobia da sociedade heterocentrista:

Era efeminado e, por não ser aceito pelos héteros nem pelos gays, me efeminei por completo e me tornei travesti. Nunca me esqueço da frase que disse quando, aos 22 anos, tomei a decisão: Vou virar travesti para ser amado. (WONDER, 2008, p. 77) 
Para colocar em xeque a "verdade” fisiológica nas construções de gênero, nos conta, em "Entre Deus e o diabo, um bisturi", que "nasceu intersexo, mas com dois meses de idade [seu] pênis apareceu e desenvolveu-se normalmente, como qualquer menino" (WONDER, 2008, p. 177). Ao descrever esse percurso, acrescenta que por pouco a sua família acatara a orientação médica para uma operação de "mudança de sexo", o que seria "uma castração pura e simples. E isso é muito mais comum do que imaginamos" (p. 177). Assim, ao trazer essa memória, faz uma denúncia, já que os saberes médicos têm, ainda na contemporaneidade, muitas vezes determinado cirurgias nos processos de construção de gênero. Ao compartilhar a sua vivência, compreensão e questionamentos sobre o seu processo de transição, desnuda os limites de padrões identitários binários e inclui a discussão sobre o direito à não-binariedade de gênero, à época, reconhecido como androginia ${ }^{14}$ :

Como a sociedade denomina o gênero de uma pessoa em seu sexo biológico, a discussão fica limitada na bipolarização de gêneros da qual a androginia não faz parte. Porém a androginia sempre esteve presente na história da humanidade. [...] Precisamos acabar com esse preconceito ridículo de que homem feminino e mulher masculina não são aceitáveis. (p. 77)

Porém, como desabafa, embora "Há anos defend[a] a ambiguidade como identidade para as pessoas transgêneros” (p. 71), trata-se de uma defesa que ainda não encontra respaldo no Brasil, pois “[...] a identidade de gênero é definida de acordo com o sexo biológico da pessoa, homem ou mulher [...]” (p. 71). Tais perspectivas irrompem como contributo para a desconstrução de estigmas e invalidações para a identidade trans e premissas para a despatologização dessa identidade, um debate ainda hoje não vencido no Brasil, apesar dos avanços.

Para garantir visibilidade qualificada para existências como a sua, Claudia Wonder dedica, de modo especial, três das sete seções da obra: “Trabalho e profissão", "Entrevistas" e "Perfis”. Um conjunto textual que, de forma mais personificada, tanto performa um espaço acolhedor de/para uma multiplicidade trans, quanto desconstrutor de estereótipos e estigmas sobre esse existir.

Destaca-se que, ao escolher como seção de abertura da obra "Trabalho e Profissão”, a autora publicizará a trajetória de sucesso profissional de diferentes mulheres trans, que, apesar das violências sofridas, alcançaram reconhecimento nas mais diversas áreas profissionais - imprensa, justiça, televisão, teatro, educação, artes plásticas. Entretanto, na crônica "O preço da dignidade” (p. 21), faz ecoar no desabafo de uma de suas leitoras, Lizandra Costa, o seu próprio, pois tanto uma quanto a outra têm lutado para resistir aos extermínios no mercado de trabalho. Como desfecho desse engajamento, grita: "Acreditar que transgêneros só trabalham como cabelereiras, artistas ou prostitutas é um estereótipo, ou seja, uma ideia preconcebida” (p. 26).

Em "Entrevistas e Perfis", ao evidenciar a história de 13 mulheres trans brasileiras e estrangeiras, incluindo sua própria história na crônica "Entrevistas, $\mathrm{O}$ mito volta à cena - Entrevista com Claudia Wonder, por Paulo Giacomini” (p. 50), além de confirmar a urgência em se respeitar as múltiplas formas de se entender e construir o feminino trans, garante que esses muitos modos de existir e de se entender mulher sejam enunciados em um espaço de afeto (nascimento, 2018a, 2018b).

\footnotetext{
14 De acordo com Sandra Bem (1974) apud Maria Cristina Ferreira (1999), “[...] os indivíduos andróginos seriam mais flexíveis e livres no desempenho dos papéis de gênero, sendo capazes de exibir comportamentos masculinos, femininos ou ambos, de acordo com o que fosse mais apropriado a cada situação” (n/p). Essa concepção dialoga com o uso que Wonder (2008) faz do termo em sua crônica.
} 
Nas demais seções: “Identidade de gênero", “Outras histórias”, “Preconceito” e "Religião”, ao discutir temas cruciais que orbitam o (re)existir trans em um regime de exceção, Wonder também narrará a sua trajetória biográfica. Em "Identidade de gênero", por exemplo, ao debater o binarismo identitário, compartilha, conforme abordado anteriormente, o seu processo de transição. Quando trata da transfobia na infância, em "Histórias e agruras de uma criança trans", a autora dá seu testemunho sobre as múltiplas violências que sofreu. Já em “Outras histórias”, com uma variedade temática substancial, dirá da solidão sofrida pelos corpos trans, mas também homenagens recebidas por parte do escritor Caio Fernando Abreu e Nelson Luis Barbosa em "Homenagem a Caio Fernando Abreu I e II" (p. 104-109). Mas isso não é tudo. A cronista sublinha ainda o sentimento de comunidade que a constitui em "São Paulo, meu amor" (p. 110-111), texto dedicado à Parada do Orgulho LGBT no contexto de celebração dos 450 anos da cidade de São Paulo.

Por esses elementos narrativos acima apresentados, o narrar-se de Wonder, para além de confirmar a sua existência como digna de reconhecimento, se revela como digno de conhecimento. Mas não só. Como uma estratégia de luta, revela-se junto a outras tantas existências trans femininas e, por meio dessa multiplicidade, todas dignas de nota, insurgem agentes de um processo revolucionário, uma revolução Travolaka, que, desde os anos 2000, defendia o direito à autoidentificação, conquistado judicialmente somente em 2018, como já mencionado. A obra de Wonder, produzida naquele contexto, emblematicamente defende a vivência da identidade de gênero e consequentemente a sexualidade, sem ter de pedir permissão e, por isso, ainda muito atual. O seu narrar-se é, portanto, travolako, e, assim, capaz de se instalar como interpelação para toda a sociedade que, também submetida à compulsoriedade de um padrão binário cisheteronormativador, tem sido limitada nos modos de se pensar e se narrar o humano.

\section{CONSIDERAÇÕES FINAIS}

Como busquei demonstrar, o narrar-se trans efetivado por Ruddy $(1998,2007)$ e Wonder (2008), no contexto de redemocratização do Estado brasileiro, ainda que de forma independente das reflexões e discussões propostas pela academia sobre concepção de gênero e identidade, revela-se como fraturador de narrativas patologizadoras e estigmatizadoras quanto ao existir trans. Se nas escritas de Ruddy a estrela nasce destacadamente pela autovalorização; na de Wonder, nasce pela defesa do direito à autodefinição. Esses textos representam, portanto, guinadas nos modos do aparecer trans no espaço literário, particularmente se comparados com as autobiografias de Nery (1984) e Ádreon (1985), ainda circunstanciadas a um contexto da patologização e criminalização dessa identidade. Assim, se Nery e Ádreon tiveram de manejar esforços para defender o direito a uma identidade patologizada, sob o risco de prisão; nos anos 1990-2000, Ruddy e Wonder se valem de um Estado democrático de direito para assumirem o estrelato, não mais limitadas a uma narrativa de "nascida em um corpo errado". Essas escrituras, de modos diferentes, colocam em xeque narrativas de impossibilidades impostas para suas existências, redesenham roteiros pré-estabelecidos paras suas vidas e para outras vidas - estrelam, como deve ser, "luzindo em nossas vidas". 


\section{REFERÊNCIAS}

ÁDREON, Loris. Meu corpo, minha prisão: autobiografia de um transexual. Rio de Janeiro: Marco Zero, 1985.

ARAN, Márcia. “A transexualidade e a gramática normativa do sistema sexo-gênero." Ágora, Rio de Janeiro, v. 9, n. 1, jun. 2006, p. 49-63, jun. 2006. Disponível em: http://www.scielo.br/scielo. php?script=sci_arttext\&pid=S1516-14982006000100004\&lng=en\&nrm=isso.

ARARUNA, Maria Léo, org. Nós, trans: escrevivências de resistência. São Paulo: LiteraTrans, 2017.

BANDEIRA, Manuel. “A estrela.” In: Poesia completa e prosa. Rio de Janeiro: José Aguilar, 1967.

BENTO, Berenice. A reinvenção do corpo: sexualidade e gênero na experiência transexual. Rio de Janeiro: Garamond, 2006.

BOURDIEU, Pierre. “Os três estados do capital cultural.” In: NOGUEIRA, Maria Alice; CATANI, Afrânio (orgs.). Escritos de Educação. Petrópolis: Vozes, 2007, p. 71-79.

BRANT, T.; MOIRA, Amara; NERY, João W.; ROCHA, Márcia. Vidas Trans: a coragem de existir. São Paulo: Astral Cultural, 2017.

BRASIL. [Constituição (1988)]. Constituição da República Federativa do Brasil. Brasília: Presidência da República [2016], Disponível em: http://www.planalto.gov.br/ccivil_03/constituicao/constituição.htm.

BUTLER, Judith. Corpos em aliança e a política das ruas: notas para uma teoria performativa de assembleia. Rio de Janeiro: Civilização Brasileira, 2018.

CARVALHO, Mario; CARRARA, Sérgio. "Em direito a um futuro trans? Contribuição para a história do movimento de travestis e transexuais no Brasil.” Sex., Salud Soc. (Rio J.), Rio de Janeiro, n. 14, ago, 2013, p. 319-351. DOI: https://doi.org/10.1590/S1984-64872013000200015. Disponível em: http://www.scielo. br/scielo.php?script=sci_arttext\&pid=S198464872013000200015\&lng=en\&nrm=iso.

COACCI, Thiago. "Movimento trans em Belo Horizonte: resgatando o histórico e mapeando o presente." Cad. Pagu, Campinas, n. 55, e195518, maio de 2019. DOI: https:// doi.org/10.1590/18094449201900550018. Disponível em: http://www.scielo.br/scielo. php?script=sci_arttext\&pid=S010483332019000100507\&lng=pt\&nrm=iso.

COLLINS, Patricia Hill. Pensamento feminista negro. Trad. Jamille Pinheiro Dias. São Paulo: Boitempo, 2019.

COSSI, Rafael Kalaf. Transexualismo, psicanálise e gênero: do patológico ao singular. 2010. 148 f. Dissertação (Mestrado em Psicologia) - Instituto de Psicologia, Universidade de São Paulo, São Paulo, 2010.

D’ALESSANDRO, Porcina. Trinta anos de reclusão e as memórias de Porcina D’Alessandro. São Paulo: LiteraTrans, 2017.

FERREIRA,MariaCristina. “Identidadedegêneroeatitudessobreamulher." Psicologia:TeoriaePesquisa,Brasília, v. 15, n. 3, dez. 1999, p. 249-255.DOI: https://doi.org/10.1590/S0102-37721999000300008. Disponível em: http://www.scielo.br/scielo.php?script=sci_arttext\&pid=S010237721999000300008\&lng=en\&nrm=iso.

FRANÇA, Thiago Alves. Memória, constituição e discursivização de G Magazine: a homofobia, o assumir-se gay e a militância. 2010. 143 f. Dissertação (Mestrado em Memória: Linguagem e Sociedade) - Programa de Pós-Graduação em Memória, Linguagem e Sociedade, Universidade Estadual do Sudoeste da Bahia, Vitória da Conquista, 2010.

GAUDENZI, Paula. "Intersexualidade: entre saberes e intervenções." Cad. Saúde Pública, Rio de Janeiro, v. 34, n. 1, e00000217, 2018. Disponível em: http://www.scielo.br/scielo. php?script=sci_arttext\&pid=S0102311X2018000105007\&lng=en\&nrm=iso. 
GOFFMAN, Erving. Estigma: notas sobre a manipulação da identidade deteriorada. Rio de Janeiro: Zahar, 1988.

GUIMARÃES, Amanda. Meu nome é Amanda: \#trans\#mandycandy\#youtube. Rio de Janeiro: Rocco, 2016.

HERZER, Anderson. A queda para o alto. 25. ed. São Paulo: Vozes, 2007.

JESUS, Jaqueline Gomes de. "Pessoas transexuais como reconstrutoras de suas identidades: reflexões sobre o desafio do direito ao gênero." In: SIMPÓSIO GÊNERO E PSICOLOGIA SOCIAL DIÁLOGOS INTERDISCIPLINARES, 2010, Brasília. Anais [...]. Brasília: Universidade de Brasília, 2010. Disponível em: https://www.researchgate.net/publication/233869298_Pessoas_transexuais_como_reconstrutoras_de_ suas_identidades_reflexoes_sobre_o_desafio_do_direito_ao_genero.

JESUS, Jaqueline Gomes de. "Transfobia e crimes de ódio: Assassinatos de pessoas transgênero como genocídio." In: MARANHÃO FILHO, Eduardo Meinberg de Albuquerque, (org.). “(In)Visibilidade Trans 2”. História Agora, v. 16, n. 2, 2013, p. 101-123.

LEJEUNE, Philippe. O pacto autobiográfico: de Rousseau a internet. Belo Horizonte: UFMG, 2014.

LESSA, Jô. Eu trans - A alça da bolsa: relatos de um transexual. Rio de Janeiro: Metanóia, 2014.

LIONÇO, Tatiana. "Que direito à saúde para a população GLBT? Considerando direitos humanos, sexuais e reprodutivos em busca da integralidade e da equidade.” Saúde Sociedade, São Paulo, v. 17, n. 2, jun. 2008, p. 11-21. Disponível: http://www.scielo.br/scielo. php?script=sci_arttext\&pid=S010412902008000200003\&lng=en\&nrm=iso.

LIONÇO, Tatiana. Um olhar sobre a transexualidade a partir da perspectiva da tensionalidade somato-psíquica. Brasília. 2006. 158 f. Tese (Doutorado em Psicologia) - Instituto de Psicologia - Universidade de Brasília, Brasília, 2006.

LOURO, Guacira Lopes, org. O corpo educado: pedagogias da sexualidade. Belo Horizonte: Autêntica, 2000.

LOURO, Guacira Lopes. Gênero, sexualidade e educação: uma perspectiva pós-estruturalista. Petrópolis: Vozes, 1997.

MARCUSCHI, Luiz Antônio. "Gêneros textuais: definição e funcionalidade." In: DIONISIO, Angela Paiva; MACHADO, Ana Rachel; BEZERRA, Maria Auxiliadora, (orgs.). Gêneros textuais e ensino. Rio de Janeiro: Lucerna, 2005. p. 19-36.

MOIRA, Amara. "Levantamento de obras brasileiras de autoria trans e/ou queer." Facebook: Amara Moira. 10 de julho de 2020. https://www.facebook.com/amoiramara.

MOIRA, Amara. "Transgressões da primeira autora trans." Suplemento Cultural do Diário Oficial do Estado, s/l, 05 fev. 2018. Disponível em: https://www.suplementopernambuco.com.br/artigos/2041transgress\%C3\%B5es-da-primeira-autora-trans.html.

MOIRA, Amara. E se eu fosse puta. São Paulo: Hoo editora, 2016.

MOMBAÇA, Jota. Pode um cu mestiço falar? s/1: s/n, 06 jan. 2015. https://medium.com/@jotamombaca/ pode-um-cu-mestico-falar-e915ed9c61ee.

MURTA, Daniela. Os desafios da despatologização da transexualidade: reflexões sobre a assistência a transexuais no Brasil. 2011. 107 f. Tese (Doutorado em Saúde Coletiva) - Instituto de Saúde Social, Universidade Federal do Rio de Janeiro, Rio de Janeiro, 2017.

NASCIMENTO, Tatiana. "Da palavra queerlombo ao cuíerlombo da palavra. Palavra, preta! poesia di dendê." s/1, 12 mar. 2018b. Disponível em: https://palavrapreta.wordpress.com/2018/03/12/cuierlombismo/ 
NASCIMENTO, Tatiana. "O cuíerlombo da palavra (y da palavra queerlombo...) > poesia preta lgbtqi de denúncia da dor até direito ao devaneio." In: ARAÚJO, Adriana de Fátima Barbosa; SOUTO, Suzana (orgs.). I Encontro Ler: literatura, estética e revolução. Brasília: Universidade de Brasília, 2018a. p. 8-23.

NERY, João W. Erro de pessoa: Joana ou João? O depoimento de um transexual brasileiro que, nascido mulher, finalmente se realizou como homem. Rio de Janeiro: Record, 1984.

NERY, João W. Velhice Transviada: Memórias e reflexões. Rio de Janeiro: 2019.

NERY, João W. Viagem solitária: memórias de um transexual trinta anos depois. São Paulo: Leya, 2011.

PEREIRA, Cleyton Feitosa. "Movimento LGBT e Partidos Políticos Construindo uma Agenda de Pesquisa." Cadernos GenDiv, Salvador, v. 3, n. 4, out.-dez. 2017, p. 125-132. https://portalseer.ufba.br/index.php/ cadgendiv

PISCITELLI, Adriana; ASSIS, Gláucia de Oliveira; OLIVAR, José Miguel Nieto (orgs.). Gênero, sexo, amor e dinheiro: mobilidades transnacionais envolvendo o Brasil (Coleção Encontros). Campinas: UNICAMP/ PAGU, 2011.

QUEIROZ, Téhh. A vida de um transgênero. Maringá: Viseu, 2018.

RUDDY. Liberdade ainda que profana. Rio de Janeiro: Razão Cultural, 1998.

RUDDY. Nem tão bela, nem tão louca. Rio de Janeiro: Razão Cultural, 2007.

SILVA, Tomaz Tadeu da. "A produção social da identidade e da diferença." In: SILVA, Tomaz Tadeu da, org. Identidade e diferença: a perspectiva dos estudos culturais. Rio de Janeiro: Vozes, 2014. p. 73-102.

SILVA, Tomaz Tadeu da. Antropologia do ciborgue: as vertigens do pós-humano. Belo Horizonte: Autêntica, 2000.

SOARES, Luiz Henrique Moreira; LOPES, Rosiney Aparecida. "Ela é amapô de carne, osso e palavras: personagens travestis no romance contemporâneo brasileiro." Revista do Instituto de Políticas Públicas de Marília, Marília, v. 3, n. 1, jan./jun. 2017, p. 79-96. http://www2.marilia.unesp.br/revistas/index.php/ RIPPMAR/article/view/7391

TREVISAN, João Silvério. Devassos no paraíso: a homossexualidade no Brasil da colônia à atualidade. Rio de Janeiro: Objetiva, 2018.

VERGUEIRO, Viviane Simawaka. Por inflexões decoloniais de corpos e identidades de gênero inconformes: uma análise autoetnográfica da cisgeneridade como normatividade. 2015. 243 f. Dissertação (Mestrado em Programa Multidisciplinar de Pós-Graduação em Cultura e Sociedade) - Instituto de Humanidades, Artes e Ciências Professor Milton Santos, Universidade Federal da Bahia, Salvador, 2015.

VIANNA, Cláudia Pereira. "O movimento LGBT e as políticas de educação de gênero e diversidade sexual: perdas, ganhos e desafios.” Educação Pesquisa, São Paulo, v. 41, n. 3, jul./set. 2015, p. 791-806.

WONDER, Claudia. Olhares de Claudia Wonder: Crônicas e outras histórias. São Paulo: GLS, 2008.

WOODWARD, Kathryn. "Identidade e diferença: uma introdução teórica e conceitual." In: SILVA, Tomaz Tadeu da, org. e trad. Identidade e diferença: a perspectiva dos estudos culturais. Petrópolis: Vozes, 2014. p. 7-72. 